\title{
Finite Element Analysis of Delamination in Drilling Composite Laminates
}

\author{
Ibrahim A. Imam \\ Mechanical Engineering, Faculty of Engineering \\ King Abdulaziz University \\ Saudi Arabia
}

\begin{abstract}
Composite materials are being strongly used in aerospace, automobile and daily life applications. Owing to their high strength, stiffness with low density and light weight. Drilling process on composites is required to assemble components with rivets and bolts. Delamination is one of the most critical defects occurs for composite material due to thrust force caused by the process of drilling. The study investigated how the speed of drill bit rotation and feed rate effected on quality of drill hole. Abaqus is a Finite element software the has been used to study delamination. The material is $\mathrm{T300/634}$ and laminate layup was. $[45,90,-45,0]$. The spindle speed was $12000 \mathrm{r} / \mathrm{min}$ and feed rate range between 0.005 to $0.05 \mathrm{~mm} / \mathrm{rev}$. The results provide strong evidence that thrust force increases in direct proportion with increasing feed rate. The speed of the spindle may be important and should be tested investigated for its possible effects on delamination.
\end{abstract}

Keywords - Thrust force, Finite elements, Delamination, Feed rate, Composites.

\section{INTRODUCTION}

Material technology has continually evolved over the years with the emerging trend being the development of composite materials. The military, aerospace, transportation and automotive industries greatly take advantage of the improved properties of the laminated composite materials since they can be easily manufactured [1]. Furthermore, laminated composites are subjected to machining to obtain functional upshots, hence; fabrication is dependent on the efficiency and effectiveness of drilling. In the field of electrical and mechanical engineering, the Glass Fiber Reinforced Plastic (GFRP) composites are extensively applied because of their superior properties over the traditional materials, for instance, they have a high stiffness to weight, dimensional stability, higher specific strength to weight ratios, corrosion resistance, lighter weight, and flexibility in design. Other properties include a high level of thermal resistance, fatigue strength, and damping properties. This literature review focuses on analyzing how to make a numerical or finite element model by computer (simulation software "Abaqus") to predict the delamination and thrust force when drilling process applied on Glass fiber composite.

Machining of composites is a critical process in the drilling of holes in GFRP and manufacturing operations [1] Nonetheless, it is regarded as a major concern in contemporary manufacturing process since the material properties are nonhomogeneous. It is usually very difficult to drill a non-defective polymer composite material despite their excellent mechanical properties. Fiber pulls out, delamination, and tool wear are the major concerns while drilling the materials. Available empirical evidence proves that torque (tq) and thrust force (th) have a substantial impact on delamination and tool life [2]. Hence, to enhance the drilling performance, it is critical to analyze or predict the thrust force and torque since the process can be regarded as highly complex and dynamic characterized by advanced geometrical interactions and friction [3]. Fiber Reinforced Plastic (RFP) was extensively used in manufacturing aircraft components and submarine parts in the post-World War II. Since the 1990s, engineers and scientists have modeled and validated the cutting force and thrust force in drilling the FRP composites.

This study is concentrating on improve drill holes in composite. Analyze and study the behavior of laminates machined by drilling needed to understand what affects the thrust force and delamination. Finite elements model will be used to evaluate the delamination. By using validated Abaqus model for drilling process, the performance needs to investigate for every parameter in question.

\section{METHODOLOGY AND NUMERICAL SIMULATION}

Drilling in composite workpiece process will be investigated FEA. The FEA model will be validated by Zhang Analytical model [4], which was based on linear elastic fracture mechanics. It was stated previously that the primary cause of delamination in composite materials was due to thrust force. The process of drilling can be simulated by considering a few important parameters such as drill bit material and design, and speed and feed rate of the drill bit will alter the thrust force, both increasing and decreasing. The model demonstration will be divided into two main components - the drill bit and workpiece.

\section{A. Drill Bite}

Drilling in composite workpiece process will be investigated FEA. The FEA model will be validated by Zhang Analytical model [4], which was based on linear elastic fracture mechanics. It was stated previously that the primary cause of delamination in composite materials was due to thrust force. The process of drilling can be simulated by considering a few important parameters such as drill bit material and design, and speed and feed rate of the drill bit will alter the thrust force, both increasing and decreasing. The model demonstration will be divided into two main components - the drill bit and workpiece.

\section{TABLE I. TUNGSTEN CARBIDE PROPERTIES}

\begin{tabular}{lllll}
\hline $\begin{array}{l}\text { Mechanical } \\
\text { Property }\end{array}$ & & Unit & Unit \\
\hline Density & 15630 & $\mathrm{~kg} / \mathrm{m} 3$ & $1.56 \mathrm{E}-05$ & $\mathrm{~kg} / \mathrm{mm} 3$ \\
Youngs Modulus & 600 & $\mathrm{GPa}$ & 600000 & $\mathrm{MPa}$ \\
Poisson's ratio & 0.2 & & & \\
Yield strength & 370 & $\mathrm{Mpa}$ & & \\
Plastic Strain & $8 \%$ & 0.08 & & \\
\hline
\end{tabular}


Tungsten carbide plastic - properties

\begin{tabular}{llll}
\hline $\mathrm{A}$ & Yield strength & 370 & $\mathrm{MPa}$ \\
$\mathrm{B}$ & Hardening modulus & 17000 & $\mathrm{MPa}$ \\
$\mathrm{m}$ & Thermal soften coefficient & 0 & \\
$\mathrm{n}$ & Hardening coefficient & 9 & \\
\hline
\end{tabular}

\section{B. Composite Workpiece}

In this study, T300/634 Carbone fiber represents the material of the workpiece. This material is typically used in the Aerospace field for many reasons, including its high quality and reliability. The composite properties are presented in Table 2 [4]. The laminate lay-up and workpiece sequence are $[45,90,-45,0]$ as illustrated in Fig. 1.

TABLE II. T300/634 PROPERTIES

\begin{tabular}{llllll}
\hline $\begin{array}{l}E_{L} \\
(\mathrm{GPa})\end{array}$ & $\begin{array}{l}E_{r} \\
(\mathrm{GPa})\end{array}$ & $\begin{array}{l}E_{L T} \\
(\mathrm{GPa})\end{array}$ & $V_{L T}$ & $\begin{array}{l}\mathrm{G}_{\mathrm{IC}} \\
\left(\mathrm{J} / \mathrm{m}^{2}\right)\end{array}$ & $\begin{array}{l}\text { Ply thickness } \\
(\mathrm{mm})\end{array}$ \\
\hline 133 & 7.7 & 4.2 & 0.33 & 300 & 0.1 \\
\hline
\end{tabular}

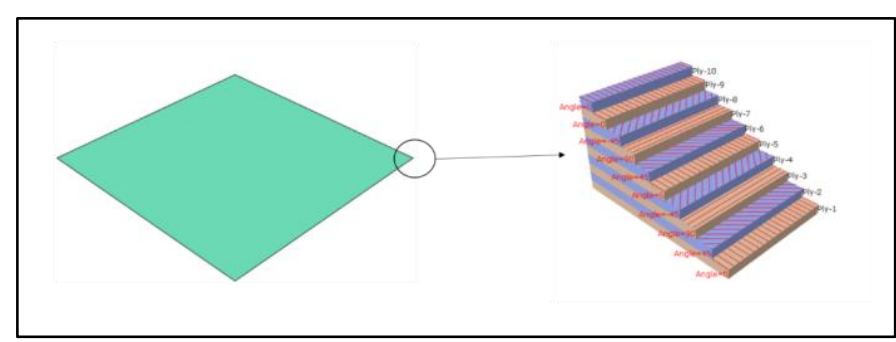

Fig. 1. Composite layup of the workpiece

\section{Boundary Conditions}

The model has two main boundary conditions. First, is the frame of the workpiece, and second is the rotation and translation of the drill bit along the workpiece; both are shown in Fig. 2. The model will be implemented twice to first validate the model and then investigate possible improvements. Initial rotational speed is $12000 \mathrm{r} / \mathrm{min}$. The Zhang [4] model investigated different layup for the composites. In the next chapter, this investigation will be used as a basis to validate our model.

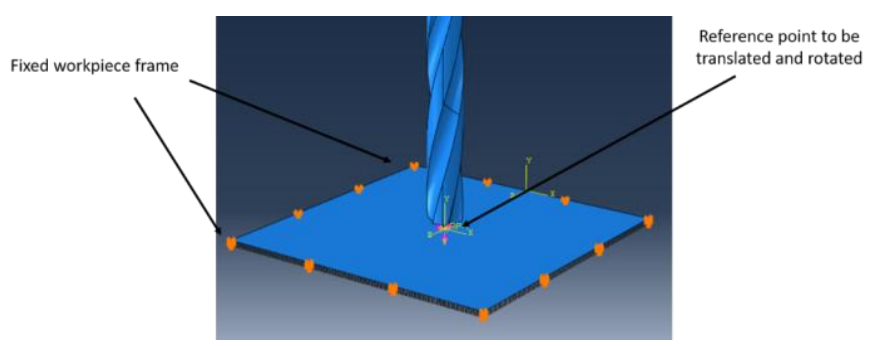

Fig. 2. Boundary conditions

The drill bit is positioned perpendicular to the workpieces and will simulate the pressing effect on composites. The elasticity effect will be determined, and damage will not occur to the material during this test as shown in Fig. 3.

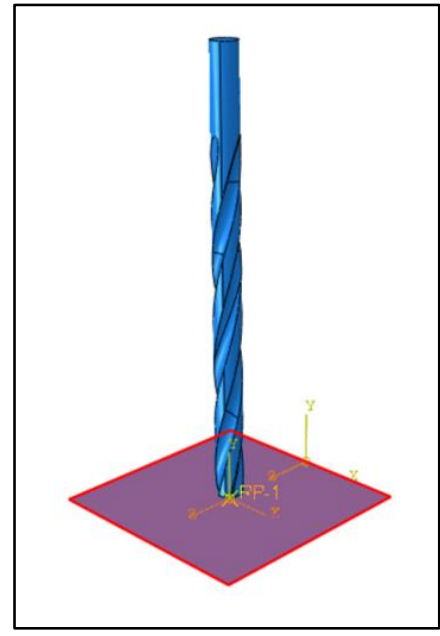

Fig. 3. Drilling configuration

\section{RESULTS AND DISCUSSIONS}

The model of Zhang et al. [4] is comprised of the initial parameters shown in the Table 3. The feed rate is the largest contributor to the model and spindle speed can be ignored because the model has no penetration. The study was performed using a spindle speed of $12000 \mathrm{r} / \mathrm{min}$ and a feed rate ranging between 0.005 to $0.05 \mathrm{~mm} / \mathrm{rev}$.

\section{A. Model Validation}

The validation process will start with 1 laminate and end with 10 laminates. The layup of the composites will be directional, the sequenced degrees is $[45,90,-45,0]$, and it is symmetric for more than four laminates. Fig. 4 demonstrate the pressing effect of drill bit. Table 3 reports the comparison between our model and Zhang et al. [4] and Fig. 5 obtain the similarity between models with respect to expected thrust force $\mathrm{N}$. It is obvious that the models are similar but with between 50 and $200 \mathrm{~N}$.

\section{TABLE III. THRUST FORCE COMPARISON BETWEEN ZHANG ET} AL [4] RESULTS AND OUR FEA MODEL

\begin{tabular}{lllllllllll}
\hline $\begin{array}{l}\text { Number } \\
\text { of ply }\end{array}$ & 1 & 2 & 3 & 4 & 5 & 6 & 7 & 8 & 9 & 10 \\
\hline $\begin{array}{l}\text { Zhang } \\
\text { FEA }\end{array}$ & 17.8 & 49.9 & 82.7 & 150.4 & 217.5 & 355.5 & 499.7 & 551.3 & 656.1 & 792.6 \\
Model & 80 & 250 & 400 & 350 & 450 & 410 & 600 & 670 & 850 & 1100 \\
\hline
\end{tabular}

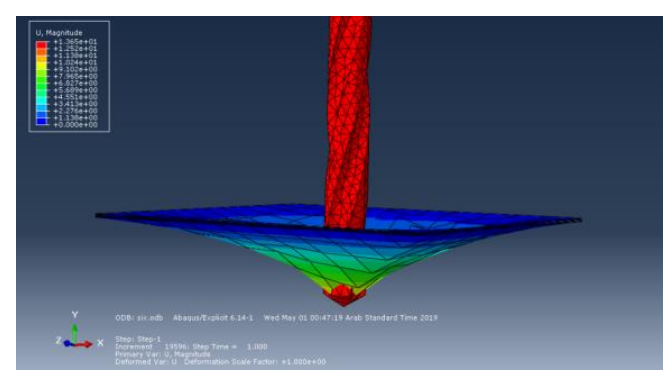

Fig. 4. Pressing effect of drill bit 


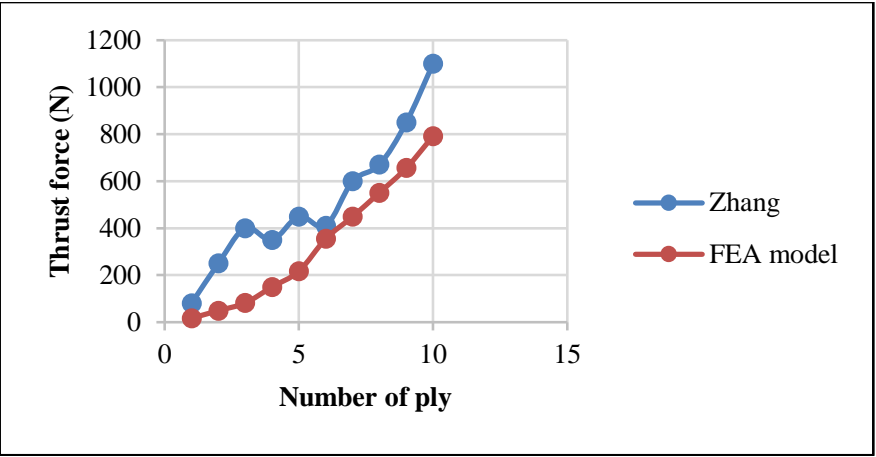

Fig. 5. FEA model validation

\section{B. Investigate Parameters}

To improve hole quality, critical parameters such as feed rate and spindle speed must to be changed several times and the results examined for changes in thrust force. In this study, we focus solely on feed rate, while spindle speed is ignored. It is clear from Table 4 and Fig. 6 that increasing feed rate results in greater thrust force.

TABLE IV THRUST FORCE FOR SEVERAL LAMINATE LAYUPS WITH SEVERAL FEED RATES

\begin{tabular}{llllll}
\hline \multirow{2}{*}{ Feed rate } & \multicolumn{5}{l}{ Number of ply } \\
& 1 & 4 & 8 & 9 & 10 \\
\hline 0.005 & 10 & 60 & 60 & 76 & 40 \\
0.01 & 50 & 175 & 175 & 170 & 200 \\
0.02 & 90 & 325 & 500 & 600 & 600 \\
0.03 & 130 & 325 & 550 & 900 & 700 \\
0.04 & 90 & 320 & 630 & 795 & 1000 \\
0.05 & 160 & 360 & 800 & 940 & 1100 \\
\hline
\end{tabular}

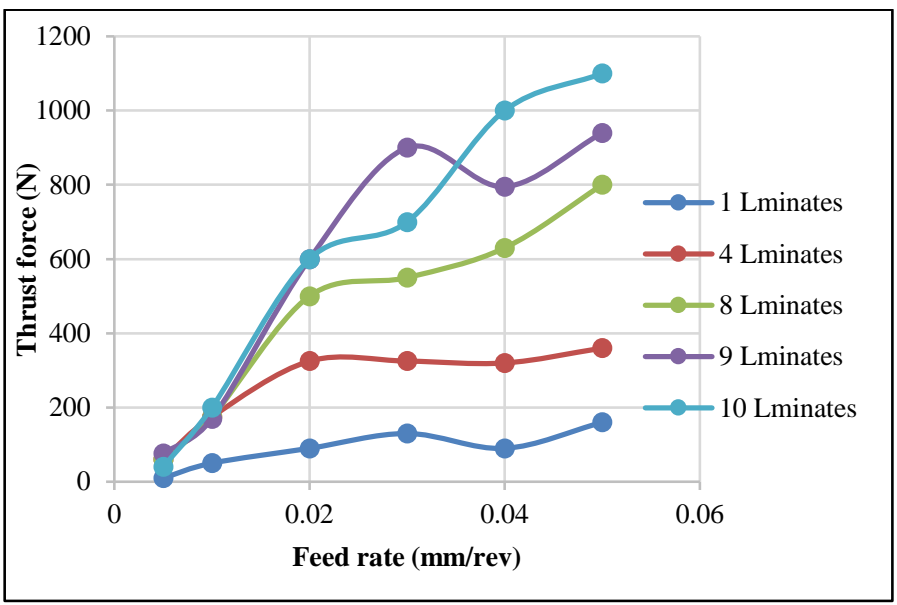

Fig. 6. Thrust force for several laminate layups with several feed rates

\section{CONCLUSIONS}

In conclusion, the results provide strong evidence that thrust force increases in direct proportion with increasing feed rate. The speed of the spindle may be important and should be tested investigated for its possible effects on delamination. Delamination is assumed to increase or decrease as a function of thrust force. The damage model is required to ensure penetration on the workpiece. Thus, delamination location is known and specified where ply is initiated. In addition, the influence of the spindle speed can be investigated. A feed rate of $0.5 \mathrm{~mm} / \mathrm{rev}$ results in higher thrust force and the lowest feed rate 0.005 $\mathrm{mm} / \mathrm{rev}$ causes lower thrust force. Thus, higher feed rate can significantly increase roughness of the workpiece hole.

It is important to acknowledge that temperature is also overlooked in this research. To increase the robustness of the study, heat parameters should be considered in the future. Drill bit material is also very important because friction between the drill bit and composite is primarily responsible for heat generation. It is recommended that future investigations explore other common materials that been used for drilling.

Careful experimentation is important to validate the model. Thus, the experimental investigation of drilling process should be coupled with analytical or numerical models.

\section{REFERENCES}

[1] L. Durão, D. Gonçalves, J. Tavares and V. Albuquerque, Drilling process of composite Laminates-A tool-based Analysis, In 14th European Conference on Composite Materials, 2010:1-10.

[2] J. Strenkowski, C. Hsieh and A. Shih, An analytical finite element technique for predicting thrust force and torque in drilling, International Journal of Machine Tools and Manufacture, 44 (12-13), 2004:1413-1421.

[3] V. Dhawan, S. Khangura and I. Singh, Prediction of Delamination Factor in Drilling Glass Fiber Reinforced Epoxy Plastics using Neural Networks, Journal of Research in Engineering and Applied Science, 2 (2), 2012:155168.

[4] L-B. Zhang, L-J. Wang and X-Y. Liu, A mechanical model for predicting critical thrust forces in drilling composite laminates, Proceedings of The Institution of Mechanical Engineers Part B-journal of Engineering Manufacture, 215 (2), 2001:135-146. 